\title{
Forecasting Credit Portfolio Risk
}

\author{
Alfred Hamerle \\ (Universität Regensburg) \\ Thilo Liebig \\ (Deutsche Bundesbank) \\ Harald Scheule
}

(Universität Regensburg)

\section{Discussion Paper}

Series 2: Banking and Financial Supervision No $01 / 2004$ 
Editorial Board:

Heinz Herrmann

Thilo Liebig

Karl-Heinz Tödter

Deutsche Bundesbank, Wilhelm-Epstein-Strasse 14, 60431 Frankfurt am Main, Postfach 1006 02, 60006 Frankfurt am Main

Tel +49 69 9566-1

Telex within Germany 41227, telex from abroad 414431, fax +49695601071

Please address all orders in writing to: Deutsche Bundesbank,

Press and Public Relations Division, at the above address or via fax No +49 69 9566-3077

Reproduction permitted only if source is stated.

ISBN 3-935821-82-4 


\begin{abstract}
The main challenge of forecasting credit default risk in loan portfolios is forecasting the default probabilities and the default correlations. We derive a Merton-style threshold-value model for the default probability which treats the asset value of a firm as unknown and uses a factor model instead. In addition, we demonstrate how default correlations can be easily modeled. The empirical analysis is based on a large data set of German firms provided by Deutsche Bundesbank. We find that the inclusion of variables which are correlated with the business cycle improves the forecasts of default probabilities. Asset and default correlations depend on the factors used to model default probabilities. The better the point-in-time calibration of the estimated default probabilities, the smaller the estimated correlations. Thus, correlations and default probabilities should always be estimated simultaneously.
\end{abstract}

Keywords: asset correlation, bank regulation, Basel II, credit risk, default correlation, default probability, logit model, probit model, time-discrete hazard rate

JEL classification: C23, C41, G21 


\section{Non-technical Summary}

Forecasting credit portfolio risk poses a challenge for the banking industry. One important goal of modern credit portfolio models is the forecast of the future credit risk given the information which is available at the point of time the forecast is made.

Thus, the discussion paper "Forecasting Credit Portfolio Risk" proposes a dynamic concept for the forecast of the risk parameters default probabilities and default correlations. The results are based on an extensive empirical analysis of a data set provided by Deutsche Bundesbank which contains financial statements for more than 50,000 German firms and a time period from 1987 to 2000.

Important results of this paper are:

1. The inclusion of macroeconomic risk drivers improves the forecast of default probabilities considerably. We included the macroeconomic variables business climate index, unemployment rate and systematic growth in new orders of the construction industry.

2. We find that a large part of co-movements can be attributed to lagged risk drivers. Thus, default rate or loss distributions can be forecasted given the values of the lagged risk drivers.

3. The model allows default probabilities to be forecasted for individual borrowers and to estimate correlations between those borrowers simultaneously. We show that asset and default correlations depend on the point in time calibration of the default probabilities. In addition a simultaneous estimation eases the validation of default probabilities. Thus, default probabilities and correlations should never be derived separately from each other.

4. The model is an empirical application of the model which is used for the calibration of risk weights by the Basel Committee on Banking Supervision. Hence, we are able to compare the estimated parameters from our model and Basel II directly. 


\section{Nichttechnische Zusammenfassung}

Die Prognose von Kreditausfallrisiken stellt eine zentrale Herausforderung für Kreditinstitute und Finanzdienstleister dar. Ein wichtiges Ziel moderner Kreditrisikomodelle ist die Prognose zukünftiger Kreditrisiken auf Basis der im Prognosezeitpunkt zur Verfügung stehenden Information.

Vor diesem Hintergrund präsentiert der Diskussionsbeitrag "Forecasting Credit Portfolio Risk“ ein dynamisches Konzept zur gemeinsamen Prognose der zentralen Risikoparameter Ausfallwahrscheinlichkeit und Ausfallkorrelation. Die empirischen Untersuchungen in dieser Arbeit basieren auf der Unternehmensbilanzdatenbank der Deutschen Bundesbank.

Wichtige Ergebnisse des Diskussionsbeitrags sind:

1. Die Berücksichtigung von makroökonomischen Einflußgrößen verbessert signifikant die Güte der Prognose von Ausfallwahrscheinlichkeiten. Als makroökonomische Einflußgrößen wurden der Ifo-Geschäftsklimaindex, die Arbeitslosenquote und die Auftragseingänge der Baubranche verwendet.

2. Ausfallwahrscheinlichkeiten und Ausfallkorrelationen können durch zeitverzögert wirkende Risikofaktoren erklärt werden. Resultierende Verlustverteilungen können deshalb bei Kenntnis der Ausprägungen der Risikofaktoren prognostiziert werden.

3. Der Modellansatz erlaubt erstmals die simultane Ermittlung von Ausfallwahrscheinlichkeiten und Ausfallkorrelationen. Mit der Point-in-Time-Kalibrierung der Ausfallwahrscheinlichkeiten nehmen die geschätzten Korrelationen ab. Des Weiteren erleichtert die simultane Schätzung die Validierung der Ausfallwahrscheinlichkeiten. Korrelationen und Ausfallwahrscheinlichkeiten sollten deshalb nicht getrennt voneinander ermittelt werden.

4. Das Modell entspricht dem des Baseler Ausschusses für Bankenaufsicht. Die geschätzten Parameter können deshalb unmittelbar mit den Basel II Vorgaben verglichen werden. 



\section{Content}

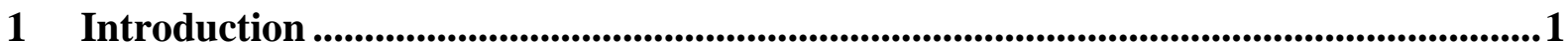

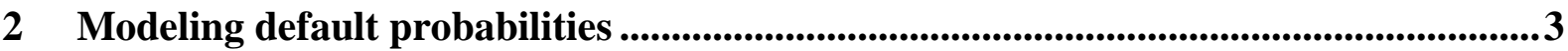

3 Modeling correlations ....................................................................................................................8

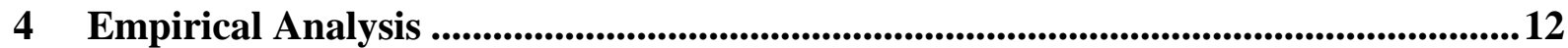

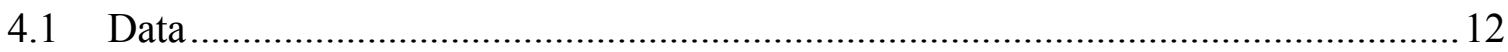

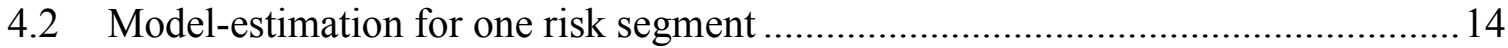

4.3 Model-estimation for multiple risk segments .................................................... 19

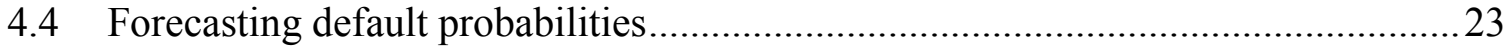

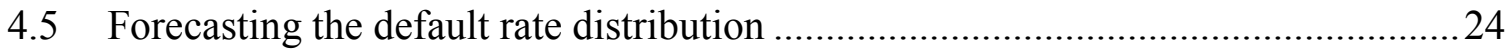

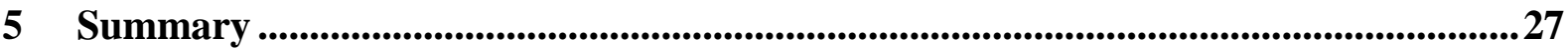

Appendix

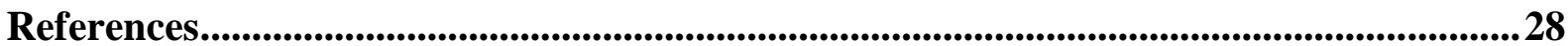





\section{Forecasting Credit Portfolio Risk ${ }^{*}$}

\section{Introduction}

The main challenge of forecasting credit default risk in loan portfolios is forecasting the default probabilities and the default correlations. They are input parameters to a variety of credit risk models like CreditMetrics ${ }^{\mathrm{TM}}$, CreditRisk+, CreditPortfolioManager ${ }^{\mathrm{TM}}$ or CreditPortfolioView ${ }^{\mathrm{TM}}$. For outlines of these models see Gupton et al. [1997], Credit Suisse Financial Products [1997], Crosbie/Bohn [2002] and Wilson [1997a, 1997b].

The main direction of modeling credit risk has its origin in the seminal model of Merton [1974, 1977] and Black/Scholes [1973]. Extensions of the approach are described in Black and Cox [1976], Merton [1977], Geske [1977], Longstaff and Schwartz [1995] or Zhou [2001]. In this model it is assumed that a default event happens if the value of an obligor's assets falls short of the value of debt. Generally speaking, one of the model's major shortcomings is the assumption of available market prices for the asset value. This is not usually valid for retail or small and medium-sized obligors.

Chart 1 displays West German insolvency rates for the years 1980 to 2000. Insolvency rates are frequently taken as proxies for default rates. It can be seen that the rates fluctuate over time. An important object of modern credit risk management is the forecast of future credit risk given the available information at the point of time at which the forecast is made.

\footnotetext{
* We would like to thank Dr. Stefan Blochwitz, Dr. Klaus Düllmann and Dr. Daniel Rösch for stimulating discussions.
} 


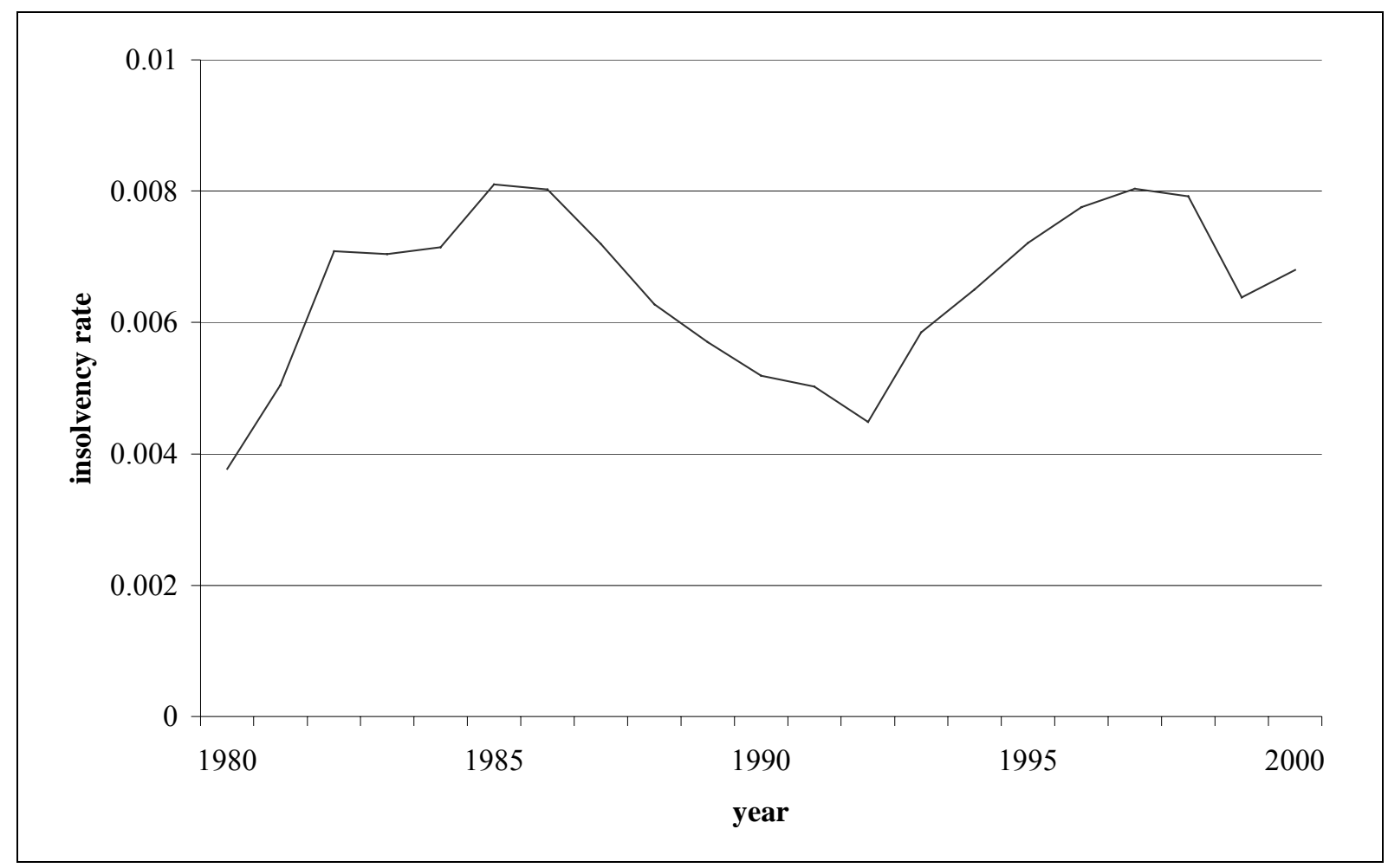

\section{Chart 1: Insolvency rates of West Germany}

In the present paper we use a model to forecast default probabilities and estimate default correlations based on the threshold model described above. The default probability measures the probability of an obligor's assets falling short of a threshold. In addition, asset correlations are modeled as a measure of co-movement of the asset values of two obligors. Default correlations can then be derived analytically.

Our approach differs from existing studies on forecasting default probabilities (such as Escott/ Glormann/ Kocagil [2001], Falkenstein [2000] and Shumway [2001]) and estimating default correlations (like Dietsch/ Petey [2002], Gupton/Finger/Bhatia [1997] and Lucas [1995]) in several ways and therefore leads to new important results. Firstly, we find that a large part of co-movements can be attributed to lagged risk drivers. Thus, default rate or loss distributions can be forecasted, given the values of the lagged risk drivers, and estimation uncertainty can be reduced. Secondly, the model we employ allows default probabilities to be forecasted for 
individual borrowers and to estimate correlations between those borrowers simultaneously. We show that asset and default correlations depend on the point in time calibration of the default probabilities. Thirdly, the model is an empirical application of the model which is used for the calibration of risk weights by the Basel Committee on Banking Supervision [2003]. Hence, we are able to compare the estimated parameters from our model and Basel II directly. As a matter of fact, we find significant differences. Fourthly, we use an extensive data set provided by Deutsche Bundesbank covering 221,684 observations of corporate balance sheet and default data. The observation period of 10 years spans more than one business cycle, which is an important requirement for the estimation of cyclical default probabilities and correlations.

The next section describes the modeling approach for default probabilities and the third section describes the modeling approach for asset and default correlations. Section 4 presents and interprets the empirical results for the data set of Deutsche Bundesbank. Section 5 provides a summary of the results and comments.

\section{Modeling default probabilities}

The event in which an obligor is unable to fulfill its payment obligations is defined as a default. The default event for obligor $i$ in the time period $t$ is random and modeled using the indicator variable $y_{i t}$, i.e.

$$
y_{i t}=\left\{\begin{array}{cc}
1 & \text { obligor } i \text { defaults in } t \\
0 & \text { otherwise }
\end{array}\right.
$$


$(i=1, \ldots, N ; t=1, \ldots, T)$. The default event is assumed to be observable.

In addition, the continuous non-observable variable $r_{i t}$ is defined, which may be interpreted as the logarithmic return of an obligor's assets. For the relationship between $r_{i t}$ and the default event $y_{i t}$ a threshold-value model is assumed. Default is equivalent to the return of an obligor's assets falling below a threshold $c_{i t}$, i.e.

$$
r_{i t} \leq c_{i t} \Leftrightarrow y_{i t}=1
$$

$(i=1, \ldots, N ; t=1, \ldots, T)$. Implicitly, a further assumption is made that no default has occurred in previous time periods. Therefore, the conditional default probability given that the obligor did not default until the beginning of the current time period

$$
\lambda_{i t}=P\left(y_{i t}=1\right)=P\left(r_{i t} \leq c_{i t}\right)
$$

is also called a time-discrete hazard rate.

We now propose a linear panel model which includes time-lagged fundamental, macroeconomic and statistical risk drivers and a contemporary systematic random effect. The model can be written as

$$
r_{i t}=\beta_{0}+\boldsymbol{\beta}^{\prime} \boldsymbol{x}_{i t-1}+\gamma^{\prime} z_{t-1}+b f_{t}+\varpi u_{i t}
$$


$(i=1, \ldots, N ; t=1, \ldots, T)$

$\boldsymbol{x}_{i t-1}$ denotes a vector of time-lagged obligor-specific risk factors such as the return on equity of the obligor's previous year's financial statement or the number of employees two years ago. Correspondingly, $z_{t-1}$ denotes a vector of systematic risk factors, like the unemployment rate of the previous year or the money market rate two years ago. The time-lagged risk factors are known at the point of time at which the forecast is given. The subscript $t-1$ represents time lags of one and more periods.

In addition, a contemporary systematic factor $f_{t}$ is included which explains the systematic risk components not captured by the model. Throughout this paper, we assume that $f_{t}$ follows a standard normal distribution.

$\beta_{0}, \boldsymbol{\beta}, \boldsymbol{\gamma}$ and $b$ are suitably dimensioned parameter vectors. Note that the notation refers to a particular risk segment such as an industry. It is assumed that the obligors are homogenous within a risk segment regarding the relevant risk factors and the factor exposures. The parameters and risk factors are allowed to differ between risk segments like industries.

In practice, the realization of the risk drivers and the default indicator $y_{i t}$ are observable while the asset returns of the latent model are not. The link between the risk factors and the probability of default (PD) is described by a threshold model. Given that default has not happened before $t$, one obtains for the conditional probability of default given the realization of the random effect $f_{t}$ (and given the values of the observable factors until time period $t-1$ ) 


$$
\begin{aligned}
\lambda\left(\boldsymbol{x}_{i t-1}, z_{t-1}, f_{t}\right) & =P\left(y_{i t}=1 \mid \boldsymbol{x}_{i t-1}, z_{t-1}, f_{t}\right) \\
& =P\left(r_{i t} \leq c_{i t} \mid \boldsymbol{x}_{i t-1}, z_{t-1}, f_{t}\right) \\
& =P\left(u_{i t} \leq \frac{c_{i t}-\beta_{0}-\boldsymbol{\beta}^{\prime} \boldsymbol{x}_{i t-1}-\boldsymbol{\gamma}^{\prime} z_{t-1}-b f_{t}}{\widetilde{\sigma}} \mid \boldsymbol{x}_{i t-1}, z_{t-1}, f_{t}\right), \\
& =F\left(\widetilde{\boldsymbol{\beta}}_{0}+\widetilde{\boldsymbol{\beta}}^{\prime} \boldsymbol{x}_{i t-1}+\widetilde{\boldsymbol{\gamma}}^{\prime} z_{t-1}+\tilde{b} f_{t}\right)
\end{aligned}
$$

where $\widetilde{\beta}_{0 i t}=\left(c_{i t}-\beta_{0}\right) / \varpi, \widetilde{\beta}=-\boldsymbol{\beta} / \varpi, \tilde{\gamma}=-\boldsymbol{\gamma} / \varpi$ and $\tilde{b}=-b / \varpi$ and $F($.$) denotes the$ distribution function of the error term $u_{i t}$. Since the threshold $c_{i t}$ cannot be observed, we restrict the intercept to $\widetilde{\beta}_{0}$.

Different assumptions about the error distribution function $F($.$) lead to different models for$ the probability of default. In the empirical analysis we use the logistic distribution function (logit model) which leads to

$$
\lambda\left(\boldsymbol{x}_{i t-1}, z_{t-1}, f_{t}\right)=\exp \left(\widetilde{\boldsymbol{\beta}}_{0}+\widetilde{\boldsymbol{\beta}}^{\prime} \boldsymbol{x}_{i t-1}+\widetilde{\boldsymbol{\gamma}}^{\prime} z_{t-1}+\widetilde{b} f_{t}\right) /\left(1+\exp \left(\widetilde{\boldsymbol{\beta}}_{0}+\widetilde{\boldsymbol{\beta}}^{\prime} \boldsymbol{x}_{i t-1}+\widetilde{\boldsymbol{\gamma}}^{\prime} z_{t-1}+\widetilde{b} f_{t}\right)\right)
$$

whereas the standardnormal distribution function $\Phi($.$) (probit model) leads to$

$$
\lambda\left(\boldsymbol{x}_{i t-1}, z_{t-1}, f_{t}\right)=\Phi\left(\widetilde{\beta}_{0}+\widetilde{\boldsymbol{\beta}}^{\prime} \boldsymbol{x}_{i t-1}+\widetilde{\gamma}^{\prime} z_{t-1}+\widetilde{b} f_{t}\right) .
$$


Note that the probit model is assumed by the Basel Committee on Banking Supervision [2003] in its Internal-Rating-Based approach in order to calculate the regulatory capital (see Finger [2001]).

Since we do not know the value of $f_{t}$ when the forecast is made we have to calculate the (expected) unconditional probability of default given by

$$
\lambda\left(x_{i t-1}, z_{t-1}\right)=\int_{-\infty}^{\infty} F\left(\widetilde{\beta}_{0}+\widetilde{\beta}^{\prime} x_{i t-1}+\widetilde{\gamma}^{\prime} z_{t-1}+\widetilde{b} f_{t}\right) \varphi\left(f_{t}\right) d f_{t}
$$

where $\varphi\left(f_{t}\right)=(1 / \sqrt{2 \pi}) \exp \left(-0,5 f_{t}^{2}\right)$ denotes the density function of the standard normal distribution.

The Parameters $\widetilde{\beta}_{0}, \widetilde{\boldsymbol{\beta}}, \widetilde{\gamma}$ and $\widetilde{b}$ can be estimated by the maximization of the expected value of the Likelihood $L(\widetilde{\beta}, \widetilde{\boldsymbol{\beta}}, \widetilde{\boldsymbol{\gamma}}, \widetilde{b})$ with respect to the distribution of the random effect $f_{t}$ over all obligors and periods of the data set:

$$
\begin{aligned}
& E\left[L\left(\widetilde{\boldsymbol{\beta}}_{0}, \widetilde{\boldsymbol{\beta}}, \widetilde{\boldsymbol{\gamma}}, \widetilde{b}\right)\right]= \\
& =\prod_{t=1}^{T} \int_{-\infty}^{\infty}\left[\prod_{i=1}^{I}\left[F\left(\widetilde{\boldsymbol{\beta}}_{0}+\widetilde{\boldsymbol{\beta}}^{\prime} \boldsymbol{x}_{i t-1}+\widetilde{\boldsymbol{\gamma}}^{\prime} z_{t-1}+\widetilde{b} f_{t}\right) y_{i t}\left(1-F\left(\widetilde{\boldsymbol{\beta}}_{0}+\widetilde{\boldsymbol{\beta}}^{\prime} \boldsymbol{x}_{i t-1}+\widetilde{\boldsymbol{\gamma}}^{\prime} z_{t-1}+\widetilde{b} f_{t}\right)\right)\left(1-y_{i t}\right)\right] \varphi\left(f_{t}\right)\right] d f_{t} .
\end{aligned}
$$

This equation contains $T$ integrals which can be solved approximately using adaptive GaussHermite-quadrature (Pinheiro/ Bates [1995] or Rabe-Hesketh/ Skrondal/ Pickles [2002], pp. 5-9). It follows from the general theory of Maximum-Likelihood estimation that the estimates exist asymptotically, are consistent and asymptotically normal distributed (Davidson/ MacKinnon [1993], pp. 243 et seq.). 


\section{Modeling correlations}

\section{Asset correlation for one risk segment}

The correlation coefficient between the latent variables $r_{i t}$ and $r_{j t}$ of two obligors $i$ and $j$ is called asset correlation $\rho\left(r_{i t}, r_{j t}\right)$ :

$$
\begin{aligned}
\rho\left(r_{i t}, r_{j t}\right) & =\frac{\operatorname{Cov}\left(r_{i t}, r_{j t}\right)}{\left.\sqrt{\operatorname{Var}\left(r_{i t}\right)} \sqrt{\operatorname{Var}\left(r_{j t}\right.}\right)}= \\
& =\frac{\operatorname{Cov}\left(b f_{t}+\varpi u_{i t}, b f_{t}+\varpi_{j t}\right)}{\sqrt{\operatorname{Var}\left(b f_{t}+\varpi u_{i t}\right)} \sqrt{\operatorname{Var}\left(b f_{t}+\omega_{j t}\right)}}= \\
& =\frac{E\left[\left(b f_{t}+\varpi u_{i t}\right)\left(b f_{t}+\overline{\omega u}_{j t}\right)\right]}{\sqrt{b^{2}+\varpi^{2} \operatorname{Var}\left(u_{i t}\right)} \sqrt{b^{2}+\varpi^{2} \operatorname{Var}\left(u_{j t}\right)}}= \\
& =\frac{b^{2} E\left(f_{t} f_{t}\right)}{b^{2}+\varpi^{2} \operatorname{Var}\left(u_{i t}\right)}= \\
& =\frac{b^{2} \operatorname{Var}\left(f_{t}\right)}{b^{2}+\varpi^{2} \operatorname{Var}\left(u_{i t}\right)}= \\
& =\frac{b^{2}}{b^{2}+\varpi^{2} \operatorname{Var}\left(u_{i t}\right)} .
\end{aligned}
$$

We assumed that $u_{i t}$ and $u_{j t}$ have the same distribution. If we assume the logistic distribution the variance of $u_{i t}$ and $u_{j t}$ equals $\pi^{2} / 3$ and the asset correlation is

$$
\rho\left(r_{i t}, r_{j t}\right)=\frac{(b / \varpi)^{2}}{(b / \varpi)^{2}+\pi^{2} / 3}=\frac{\widetilde{b}^{2}}{\widetilde{b}^{2}+\pi^{2} / 3}
$$

whereas if we assume the standardnormal distribution the variance of $u_{i t}$ and $u_{j t}$ equals 1 and the asset correlation is 


$$
\rho\left(r_{i t}, r_{j t}\right)=\frac{\tilde{b}^{2}}{\widetilde{b}^{2}+1} .
$$

\section{Asset correlation for multiple risk segments}

Sometimes it is plausible to assume that the default probabilities are driven by different risk factors for different obligors, i.e. obligors belong to different risk segments. Let obligor $i$ belong to risk segment $l$ and obligor $j$ to risk segment $m$. The model for the return on obligor $i$ 's assets is

$$
r_{i t}^{(l)}=\beta_{0}^{(l)}+\boldsymbol{\beta}^{(l)}{ }^{\prime} \boldsymbol{x}_{i t-1}^{(l)}+\boldsymbol{\gamma}^{(l)} z_{t-1}^{(l)}+b^{(l)} f_{t}^{(l)}+\varpi^{(l)} u_{i t}^{(l)}
$$

while the model for the return on obligor $j$ 's assets is:

$$
r_{j t}^{(m)}=\beta_{0}^{(m)}+\boldsymbol{\beta}^{(m)}{ }^{\prime} \boldsymbol{x}_{j t-1}^{(m)}+\boldsymbol{\gamma}^{(m)}{ }^{(m)} \boldsymbol{z}_{t-1}^{(m)}+\boldsymbol{b}^{(m)} f_{t}^{(m)}+\varpi^{(m)} u_{j t}^{(m)} .
$$

The correlation $\rho\left(r_{i t}^{(l)}, r_{j t}^{(m)}\right)$ between the latent variables $r_{i t}^{(l)}$ and $r_{j t}^{(m)}$ of two obligors is: 


$$
\begin{aligned}
\rho\left(r_{i t}^{(l)}, r_{j t}^{(m)}\right) & =\frac{\operatorname{Cov}\left(r_{i t}^{(l)}, r_{j t}^{(m)}\right)}{\sqrt{\operatorname{Var}\left(r_{i t}\right)} \sqrt{\operatorname{Var}\left(r_{j t}\right)}=} \\
& =\frac{\operatorname{Cov}\left(b^{(l)} f_{t}^{(l)}+\varpi^{(l)} u_{i t}^{(l)}, b^{(m)} f_{t}^{(m)}+\varpi^{(m)} u_{j t}^{(m)}\right)}{\sqrt{\operatorname{Var}\left(b^{(l)} f_{t}^{(l)}+\varpi^{(l)} u_{i t}^{(l)}\right)} \sqrt{\operatorname{Var}\left(b^{(m)} f_{t}^{(m)}+\varpi^{(m)} u_{j t}^{(m)}\right)}}= \\
& =\frac{E\left[\left(b^{(l)} f_{t}^{(l)}+\varpi^{(l)} u_{i t}^{(l)}\right)\left(b^{(m)} f_{t}^{(m)}+\varpi^{(m)} u_{j t}^{(m)}\right)\right]}{\sqrt{b^{(l) 2}+\varpi^{(l) 2} \operatorname{Var}\left(u_{i t}\right)} \sqrt{b^{(m) 2}+\varpi^{(m) 2} \operatorname{Var}\left(u_{j t}\right)}}= \\
& =\frac{b^{(l)} b^{(m)} E\left(f_{t}^{(l)} f_{t}^{(m)}\right)}{\sqrt{b^{(l) 2}+\varpi^{(l) 2} \operatorname{Var}\left(u_{i t}\right)} \sqrt{b^{(m) 2}+\varpi^{(m) 2} \operatorname{Var}\left(u_{j t}\right)}}= \\
& =\frac{b^{(l)} b^{(m)} \operatorname{Cov}\left(f_{t}^{(l)}, f_{t}^{(m)}\right)}{\sqrt{b^{(l) 2}+\varpi^{(l) 2} \operatorname{Var}\left(u_{i t}\right)} \sqrt{b^{(m) 2}+\varpi^{(m) 2} \operatorname{Var}\left(u_{j t}\right)}}
\end{aligned}
$$

Again, if a logit model is assumed for both risk segments the asset correlation $\rho\left(r_{i t}^{(l)}, r_{j t}^{(m)}\right)$ is:

$$
\rho\left(r_{i t}^{(l)}, r_{j t}^{(m)}\right)=\frac{\widetilde{b}^{(l)} \tilde{b}^{(m)} \operatorname{Cov}\left(f_{t}^{(l)}, f_{t}^{(m)}\right)}{\sqrt{\widetilde{b}^{(l) 2}+\pi^{2} / 3} \sqrt{\tilde{b}^{(m) 2}+\pi^{2} / 3}}
$$

If a probit model is assumed for both risk segments the asset correlation $\rho\left(r_{i t}^{(l)}, r_{j t}^{(m)}\right)$ is:

$$
\rho\left(r_{i t}^{(l)}, r_{j t}^{(m)}\right)=\frac{\tilde{b}^{(l)} \tilde{b}^{(m)} \operatorname{Cov}\left(f_{t}^{(l)}, f_{t}^{(m)}\right)}{\sqrt{\tilde{b}^{(l) 2}+1} \sqrt{\widetilde{b}^{(m) 2}+1}} .
$$




\section{Default correlation}

The default correlation can be derived from the asset correlation. For simplicity we assume that the obligors $i$ and $j$ belong to the same risk segment and that the default probabilities can be explained by a probit model. The default indicators $y_{i t}$ and $y_{j t}$ for different obligors $i$ and $j$ are binary random variables taking only the values 0 or 1 . For binary random variables the correlation coefficient $\rho\left(y_{i t}, y_{j t}\right)$ for period $t$ can be written as

$$
\rho\left(y_{i t}, y_{j t}\right)=\frac{\lambda\left(\boldsymbol{x}_{i t-1}, \boldsymbol{x}_{j t-1}, z_{t-1}\right)-\lambda\left(\boldsymbol{x}_{i t-1}, z_{t-1}\right) \lambda\left(\boldsymbol{x}_{j t-1}, z_{t-1}\right)}{\left.\sqrt{\lambda\left(\boldsymbol{x}_{i t-1}, z_{t-1}\right)\left(1-\lambda\left(\boldsymbol{x}_{i t-1}, z_{t-1}\right)\right)} \sqrt{\lambda\left(\boldsymbol{x}_{j t-1}, z_{t-1}\right)\left(1-\lambda\left(\boldsymbol{x}_{j t-1}, z_{t-1}\right)\right.}\right)},
$$

where $\lambda\left(\boldsymbol{x}_{i t-1}, z_{t-1}\right)$ and $\lambda\left(\boldsymbol{x}_{j t-1}, z_{t-1}\right)$ are the unconditional default probabilities and $\lambda\left(x_{i t-1}, x_{j t-1}, z_{t-1}\right)$ is the unconditional probability that both obligors $i$ and $j$ will default in period $t$ given that neither obligor has defaulted before:

$$
\lambda\left(\boldsymbol{x}_{i t-1}, \boldsymbol{x}_{j t-1}, z_{t-1}\right)=\int_{-\infty}^{\infty} F\left(\widetilde{\beta}_{0}+\widetilde{\boldsymbol{\beta}}^{\prime} \boldsymbol{x}_{i t-1}+\widetilde{\boldsymbol{\gamma}}^{\prime} z_{t-1}+\widetilde{b} f_{t}\right) F\left(\widetilde{\boldsymbol{\beta}}_{0}+\widetilde{\boldsymbol{\beta}}^{\prime} \boldsymbol{x}_{j t-1}+\widetilde{\boldsymbol{\gamma}}^{\prime} z_{t-1}+\widetilde{b} f_{t}\right) \varphi\left(f_{t}\right) d f_{t}
$$

If we assume a probit model, it can be shown that

$$
\lambda\left(x_{i t-1}, x_{j t-1}, z_{t-1}\right)=\Phi_{2}\left(\Phi^{-1}\left(\lambda\left(x_{i t-1}, z_{t-1}\right)\right), \Phi^{-1}\left(\lambda\left(x_{j t-1}, z_{t-1}\right)\right), \rho\left(r_{i t}, r_{j t}\right)\right)
$$


where $\Phi_{2}($.$) symbolizes the standardized bivariate normal distribution and \Phi^{-1}($.$) the$ quantile of the standardnormal distribution (Gupton/ Finger/ Bhatia [1997], p. 89). In conclusion, the default correlation can be derived from the unconditional default probabilities and the asset correlation of the obligors $i$ and $j$.

\section{Empirical Analysis}

\subsection{Data}

The empirical analysis is based on a data set of Deutsche Bundesbank which originally contains financial statements for up to 53,280 West German firms and a time period from 1987 to 2000. Compare Scheule [2003] for a more extensive analysis. The data is collected by Deutsche Bundesbank's branch offices in order to evaluate the credit quality of firms for refinancing purposes. The Bundesbank purchases them at the discount rate under its credit facility. An enterprise is deemed to have defaulted if insolvency proceedings have been initiated against it. The legal preconditions for the initiation of such proceedings are laid down in the German insolvency code, i.e. particularly the inability to meet due payments and overindebtedness.

In addition, the data set is extended by macroeconomic risk factors for West Germany. They cover such fields as production, consumption, income, capital markets, employment, import and export, government activity and prices. All variables are assumed to be stationary. When they show a trend, rate of returns to the previous year are used. All macroeconomic variables are lagged by one or two years.

The resulting data set is modified in several ways. The data set is restricted to the years 1991 to 2000 in order to ensure a sufficient number of observations. In addition, only West German firms are included due to the different economic developments in West and East Germany during the last decade. The firms are seperated into the industries Manufacturing, Commerce and Others. Chart 2 shows the Manufacturing industry where the insolvency rates of the 
Deutsche Bundesbank data differ from the insolvency rates of West Germany. The default rate is defined as the ratio between the number of defaulted and the total number of firms.

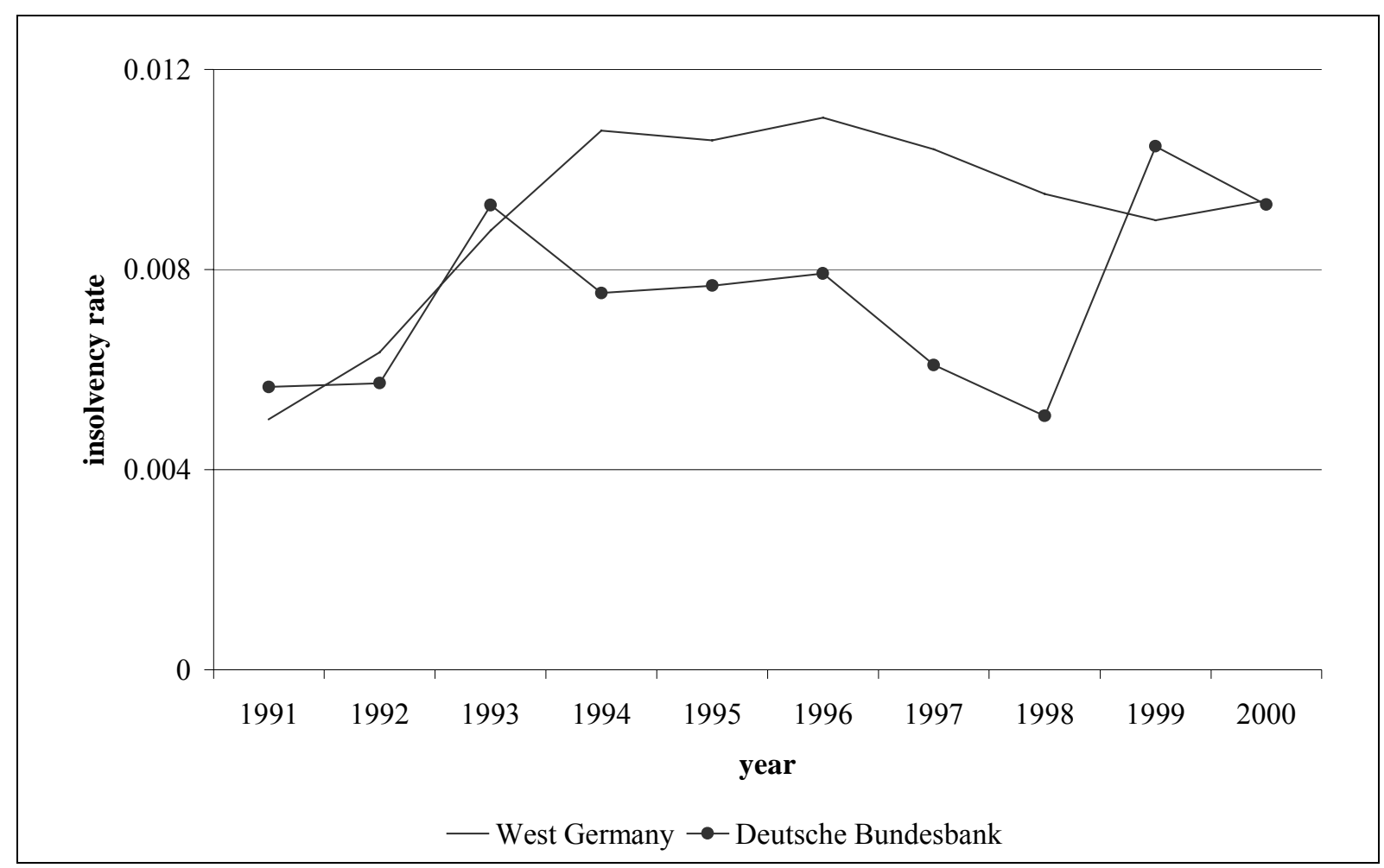

Chart 2: Default rates of the Manufacturing industry, Deutsche Bundesbank and West Germany

We assumed that the default rates for West Germany are more representative. Thus, the yearly default rates are adjusted for each industry according to the ones of West Germany by taking a random sample from either the defaults or non-defaults of each period. Table 1 shows that the resulting data set includes 221.684 observations with 1.570 defaults: 


\begin{tabular}{lcc}
\hline Industry & Observations & Defaults \\
\hline \hline Manufacturing & 88,869 & 773 \\
Commerce & 71,827 & 406 \\
Others & 60,988 & 391 \\
\hline Total & 221,684 & 1,570 \\
\hline
\end{tabular}

Table 1: Data set Deutsche Bundesbank - number of observations and defaults for different industries

The data set is divided into an estimation period 1991 to 1999 and the forecast-year 2000. Table 2 shows the number of observations and defaults of the estimation and forecast periods:

\begin{tabular}{lccc}
\hline Purpose & Period & Observations & Defaults \\
\hline \hline Estimation & $1991-1999$ & 195,476 & 1,391 \\
Forecast & 2000 & 26,208 & 179 \\
\hline Total & & 221,684 & 1,570 \\
\hline
\end{tabular}

Table 2: Data set Deutsche Bundesbank - number of observations and defaults for the estimation and forecast periods

\subsection{Model-estimation for one risk segment}

In a first step, we assume that the whole data set represents one risk segment, i.e. the default probabilities are driven by the same risk drivers and that the asset correlations are the same for all obligors. For this data set, two logit models with a random effect are estimated:

- model 1 includes only firm-specific risk drivers and

- model 2 includes firm-specific risk drivers and a systematic macroeconomic variable. 
The highest $p$-value is 0.0015 , i.e. all risk drivers are significant $(\alpha=0.05)$. The random effect represents an exception which will be explained below. Table 3 displays the estimated parameters for the two models:

\begin{tabular}{lcc}
\hline Risk driver & $\begin{array}{c}\text { Model 1 (without } \\
\text { macroeconomic risk driver) }\end{array}$ & $\begin{array}{c}\text { Model 2 (with } \\
\text { macroeconomic risk driver) }\end{array}$ \\
\hline \hline Intercept & -7.7832 & -7.8132 \\
ART & 0.0062 & 0.0062 \\
APT & 0.0123 & 0.0124 \\
CRR & -0.0324 & -0.0326 \\
ETA & -0.0162 & -0.0160 \\
MAN & 0.4045 & 0.4172 \\
RIE & -0.0014 & -0.0013 \\
TTT & 0.0308 & 0.0311 \\
GOC &. & -0.0460 \\
$b$ & 0.1205 & 0.0718 \\
\hline
\end{tabular}

Table 3: Parameter estimates for logit models with random effects, without (model 1) and with systematic macroeconomic risk driver (model 2)

The risk drivers are the

- firm-specific ratio of trade accounts receivable to total turnover (ART), ratio of notes and trade accounts payable to total turnover (APT), the capital recovery rate (CRR), the equity to assets ratio (ETA), a dummy variable for the manufacturing industry (MAN), the return on interest expenses (RIE), the transformed total turnover (TTT), and the

- $\quad$ systematic growth in new orders of the construction industry (GOC).

All risk drivers were checked for economic plausibility. Let us take the equity to assets ratio as an example. The negative parameter estimate indicates that firms with a higher equity ratio have lower default probabilities. While most risk drivers show a monotone impact on the 
default probabilities, the default rates for small and large firms (low and high total turnover) are low and for medium firms (medium total turnover) are high. Since a logit model can only include risk drivers with a monotone impact, we use the default rates of five total turnover classes and their interpolated values (transformed total turnover) presented in Chart 3 as a risk driver. We applied a cubic spline-interpolation which uses third degree polynomials. Note that the interpolated values can be interpreted as the estimated default probability given the value of the total turnover.

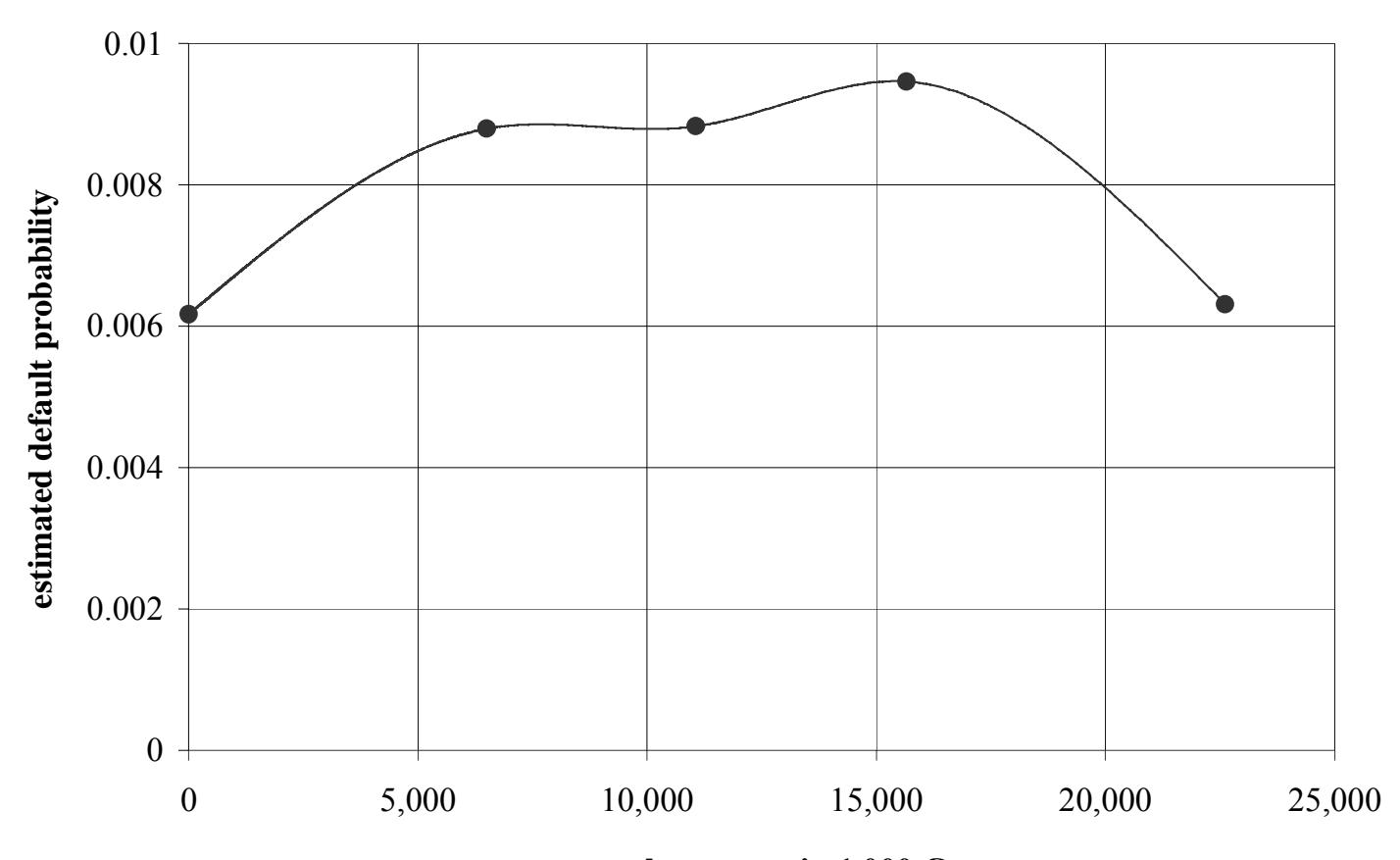

total turnover in $1,000 €$

\section{Chart 3: Estimated default probability given the total turnover}

The dummy variable for the Manufacturing industry (1: Manufacturing industry, 0: other industries) indicates that firms of this industry show a higher default probability.

The risk drivers are determined by the use of forward-, backward- and stepwise-selection methods and are scanned for stationarity. In addition, outliers are adjusted by defining a lower and an upper boundary for every risk driver. Note that the firm-specific risk drivers are lagged on average by 1.5 years while the macroeconomic risk driver of model 2 is lagged by one year. The risk drivers are calculated in percentages. A more detailed definition of the risk 
drivers and descriptive statistics is provided in the appendix. Note that macroeconomic variables are usually recorded by national institutions and published earlier than the balance sheets of firms. It should be noted that we do not claim that the risk driver is responsible for the default probabilities themselves but rather that it represents the respective point in time of the business cycle.

Chart 4 compares the real default rate with the estimated default rates of model 1 and model 2. The estimated default rate is the average of the estimated default probabilities.

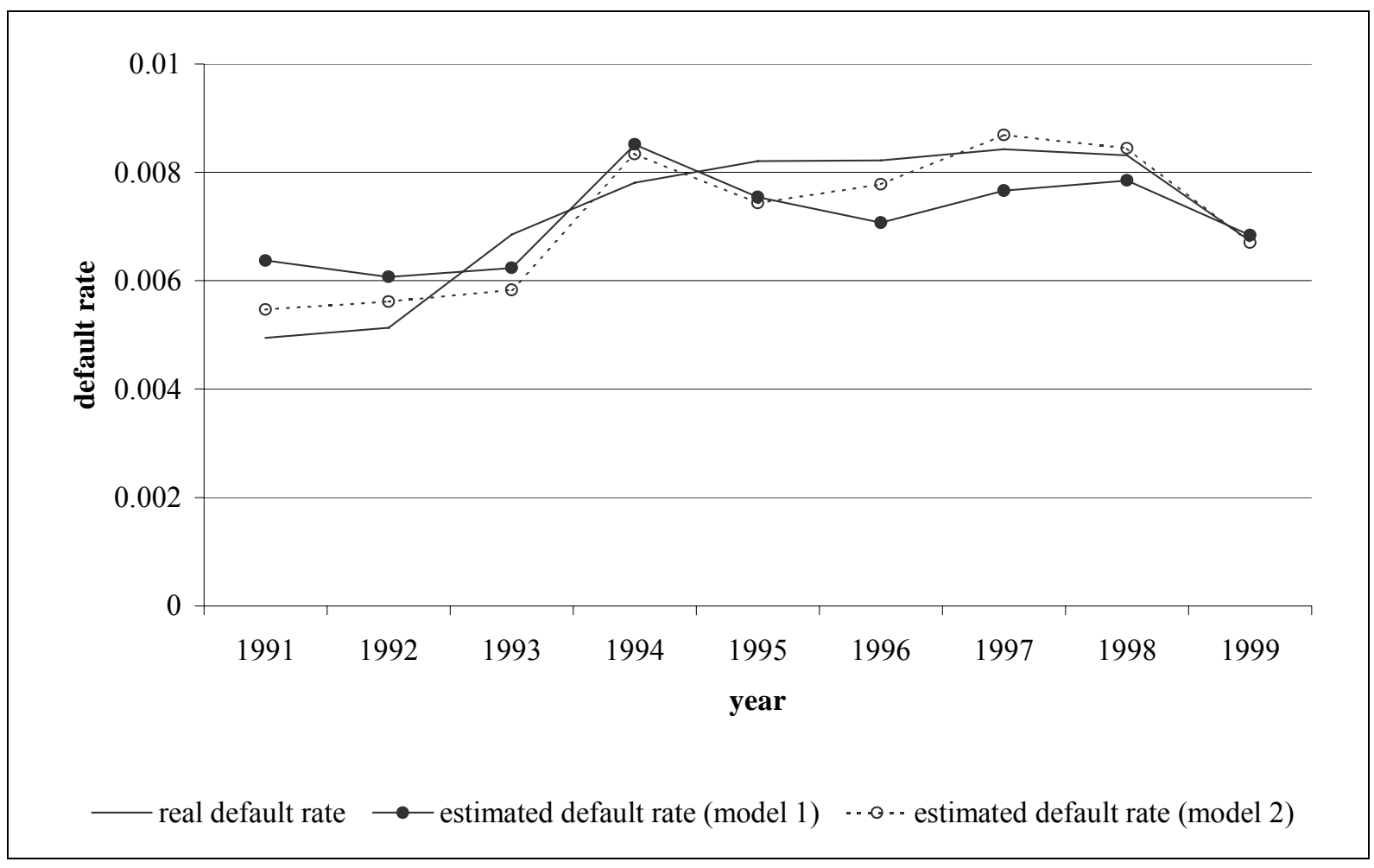

Chart 4: Real and estimated default rates for estimation period, model 1 and model 2

The calibration of the estimated to the real default rate is generally better for model 2 (with a macroeconomic variable) than for model 1 (without a macroeconomic variable). Another important property of a rating model is the power to discriminate between defaulted and nondefaulted obligors. The discrimination can be measured by the accuracy ratio (see Sobehart/ Keenan/ Stein [2000]). While the calibration of the two models differ considerably, the discrimination or accuracy ratio of model $1(0.630)$ and model $2(0.631)$ is very similar. Note that systematic macroeconomic risk drivers are the same for all obligors for a given year. 
They change all default probabilities for a given year in the same direction. Thus, the estimated default rate fits better the real default rate if systematic risk drivers are included in the logit model. This result holds for all years except 1993 and 1995.

Section 3 showed that asset correlations can be estimated by a transformation of the parameter of the random effect. Table 4 contains the asset correlation estimates for model 1 and model 2:

\begin{tabular}{lcccc}
\hline Model & Parameter estimates & Standard error & P-value & Asset correlation \\
\hline 1 & 0.1205 & 0.0333 & 0.0010 & 0.0044 \\
2 & 0.0718 & 0.0236 & 0.0833 & 0.0016 \\
\hline
\end{tabular}

Table 4: Random effect parameter and asset correlation estimates, model 1 and model 2

The inclusion of the macroeconomic risk divers results in a decrease of the estimated parameter of the random effect and therefore the asset correlation. As a matter of fact, a likelihood ratio test shows that the random effect becomes insignificant $(\alpha=0,05)$. The estimated asset correlations are considerably lower than the ones assumed by the Basel Committee on Banking Supervision [2003]. Chart 5 shows that the Basel II asset correlation for corporate exposures is a decreasing function of the default probability with values between $12 \%$ and $24 \%$ : 


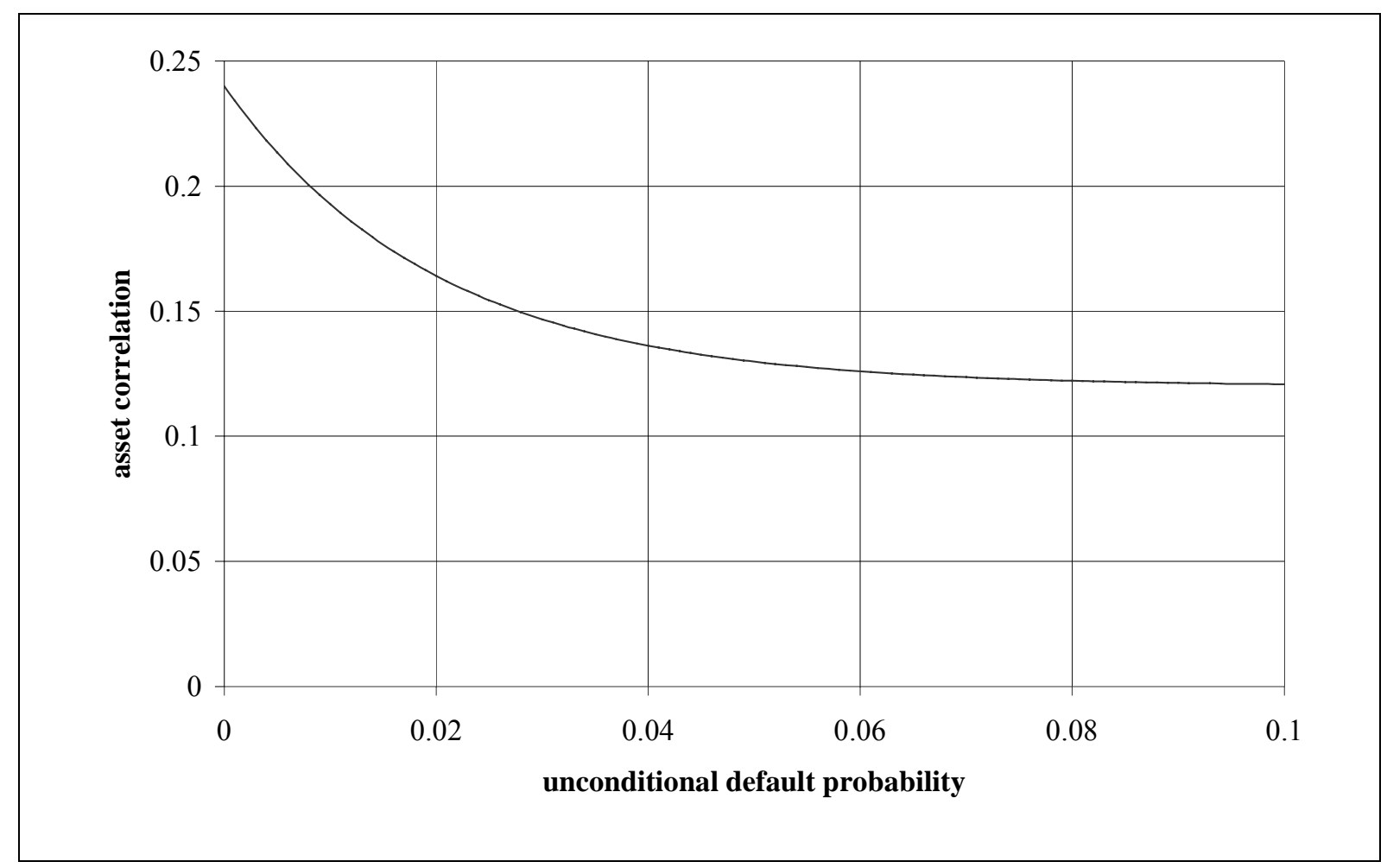

Chart 5: Basel II asset correlation for corporate exposures

\subsection{Model-estimation for multiple risk segments}

We will now assume that the industries Manufacturing, Commerce and Others define three risk segments. Again, the default probabilities within each risk segment are driven by the same risk drivers and the asset correlations are the same for all obligors. Two models are estimated which consist of one logit model with a random effect for each risk segment:

- model 3 includes firm-specific risk drivers only and

- model 4 includes firm-specific risk drivers and systematic macroeconomic variables.

Again, all risk drivers are significant $(\alpha=0,05)$. Table 5 displays the risk drivers for the two models. Note that no industry dummies are included because industry-models are estimated. 


\begin{tabular}{lcc} 
Risk segment & $\begin{array}{c}\text { Model 3 (without } \\
\text { macroeconomic risk driver) }\end{array}$ & $\begin{array}{c}\text { Model 4 (with macroeconomic risk } \\
\text { driver) }\end{array}$ \\
\hline \hline Manufacturing & ETA, APT, CRR, ITT, RIE, TTT & ETA, APT, CRR, ITT, RIE, TTT , BCI \\
Commerce & ART, ETA, APT, CRR, RIE, TTT & ART, ETA, APT, CRR, RIE, TTT \\
Others & ETA, CFT, APT, LD, RIE, TTT & ETA, CFT, APT, LD, RIE, TTT, UER \\
\hline
\end{tabular}

Table 5: Risk segment specific logit models with random effects, with (model 3) and without systematic macroeconomic risk driver (model 4)

In addition to the firm-specific risk drivers of model 1 and model 2 the cashflow to total turnover ratio (CFT) and the inventory to total turnover (ITT) are included. Again, the firmspecific risk drivers are lagged on average by 1.5 years. The risk drivers are calculated in percentages. A more detailed definition of the risk drivers and descriptive statistics is provided in the appendix. The macroeconomic risk drivers of model 4 are a business climate index $(\mathrm{BCI})$ and the unemployment rate (UER). These systematic variables are lagged by one year.

Chart 6 compares the real default rates with the estimated default rates of model 3 and model 4. Note that the estimated default probabilities of all risk segments are aggregated. 


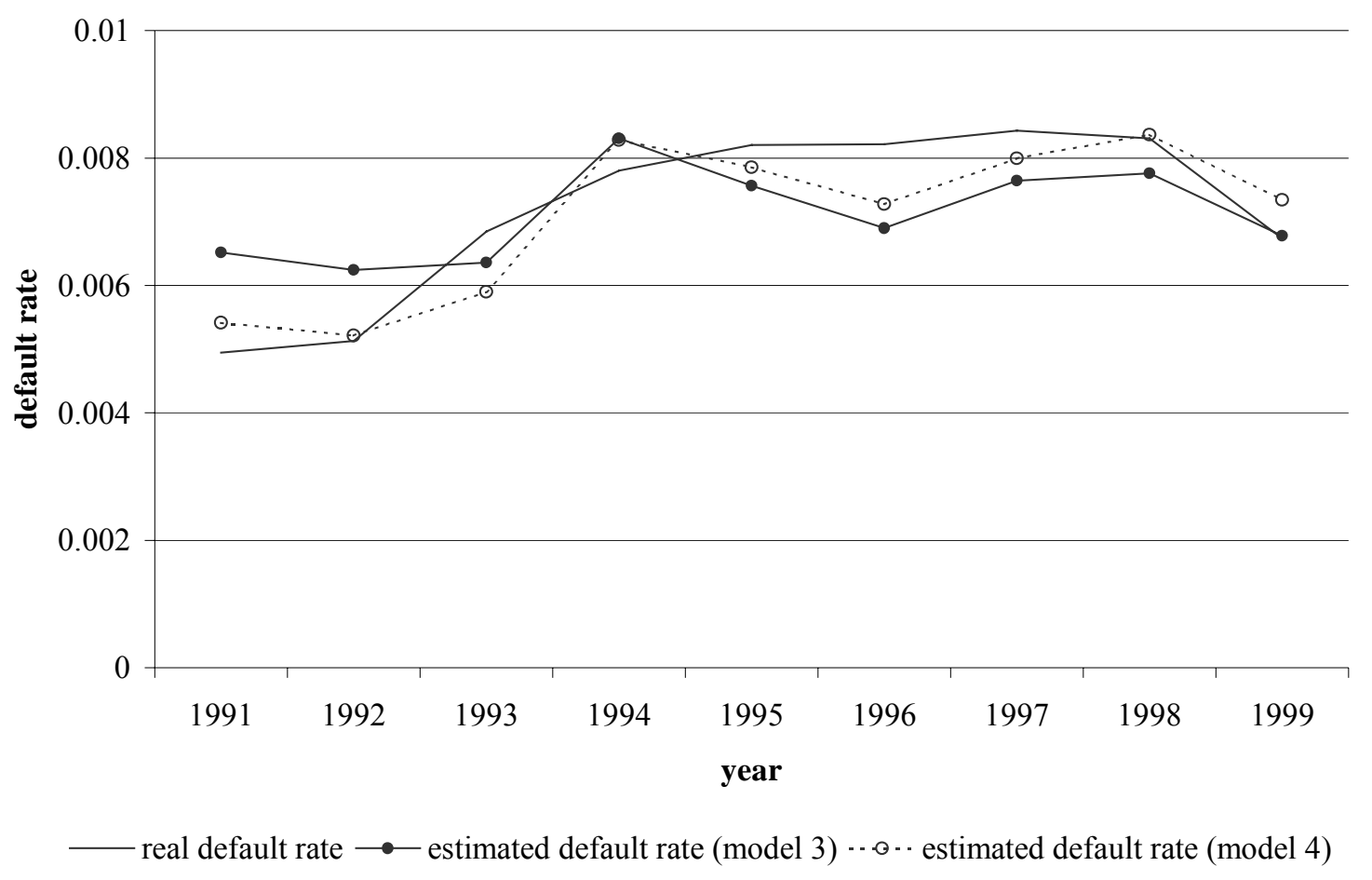

Chart 6: Real and estimated default rates for estimation period, model 3 and model 4

The results are comparable to the ones of model 1 and model 2 in the previous section. The calibration of model 3 and model 4 differ considerably while the accuracy ratio of model 3 (0.644) and model $4(0.647)$ is very similar.

Table 6 (Table 7) displays the random effect estimates for model 3 (model 4) while Table 8 (Table 9) contains the asset correlation estimates for the three risk segments.

\begin{tabular}{lccc}
\hline Risk segment & Parameter estimates & Standard error & P-value \\
\hline Manufacturing & 0.1531 & 0.0387 & 0.0013 \\
Commerce & 0.1234 & 0.0347 & 0.0495 \\
Others & 0.2130 & 0.0541 & 0.0009 \\
\hline
\end{tabular}

Table 6: Random effect parameter estimates and significance, model 3 


\begin{tabular}{lccc}
\hline Risk segment & Parameter estimate & Standard error & P-value \\
\hline \hline Manufacturing & 0.0796 & 0.0226 & 0.1167 \\
Commerce & 0.1234 & 0.0347 & 0.0495 \\
Others & 0.0990 & 0.0315 & 0.2033 \\
\hline
\end{tabular}

Table 7: Random effect parameter estimates and significance, model 4

The inclusion of the macroeconomic risk drivers results in a decrease of the estimated parameter of the random effect and therefore the asset correlation. As a matter of fact, the random effect becomes insignificant $(\alpha=0,05)$. The asset correlation of the risk segment Commerce remains unchanged because no significant macroeconomic variable was found. Note that the asset correlation of this segment in model 3 is already lower than the ones of the other segments.

Table 8 summarizes the asset correlations for obligors of the same and different risk segments for model 3 and Table 9 for model 4.

\begin{tabular}{l||ccc}
\hline & Manufacturing & Commerce & Others \\
\hline \hline Manufacturing & 0.0071 & 0.0040 & 0.0038 \\
Commerce & & 0.0046 & 0.0034 \\
Others & & & 0.0136 \\
\hline
\end{tabular}

Table 8: Asset correlation estimates, model 3

\begin{tabular}{l||ccc}
\hline & Manufacturing & Commerce & Others \\
\hline \hline Manufacturing & 0.0019 & 0.0015 & 0.0003 \\
Commerce & & 0.0046 & 0.0016 \\
Others & & & 0.0030 \\
\hline
\end{tabular}

Table 9: Asset correlation estimates, model 4 


\subsection{Forecasting default probabilities}

Time-varying variables enter the logit model with a time lag. Thus, given the estimated models 1 to 4 and the value of the risk drivers, default probabilities will now be forecasted for the year 2000. Chart 7 compares the empirical frequency distribution (class width: 0.001) of the forecasted default probabilities of model 1 and model 2:

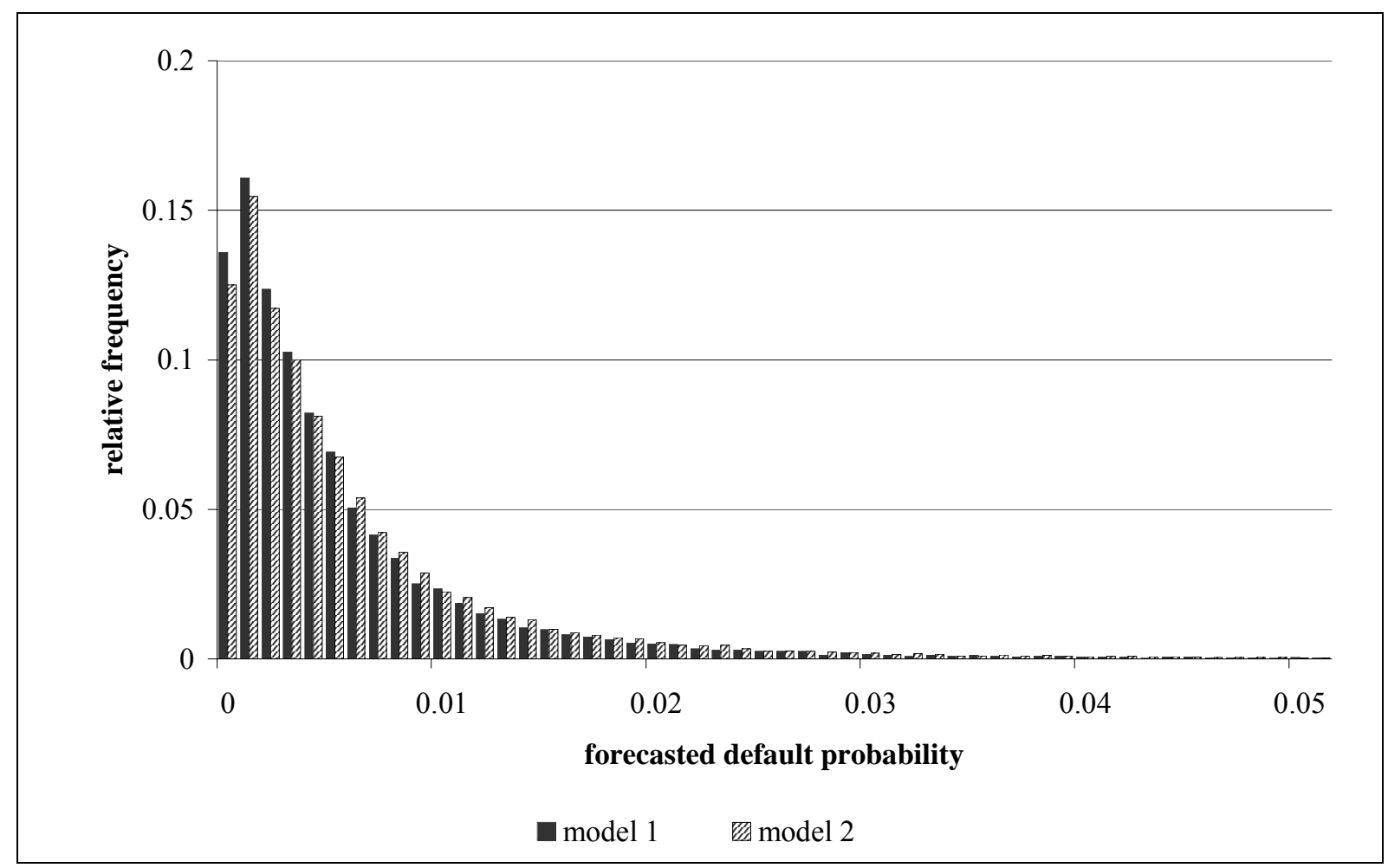

Chart 7: Frequency distribution of forecasted default probabilities, model 1 and model 2

Chart 8 compares the real and the mean forecasted default rates of model 1 to model 4 . The forecasted default rate is the average of the forecasted default probabilities. 


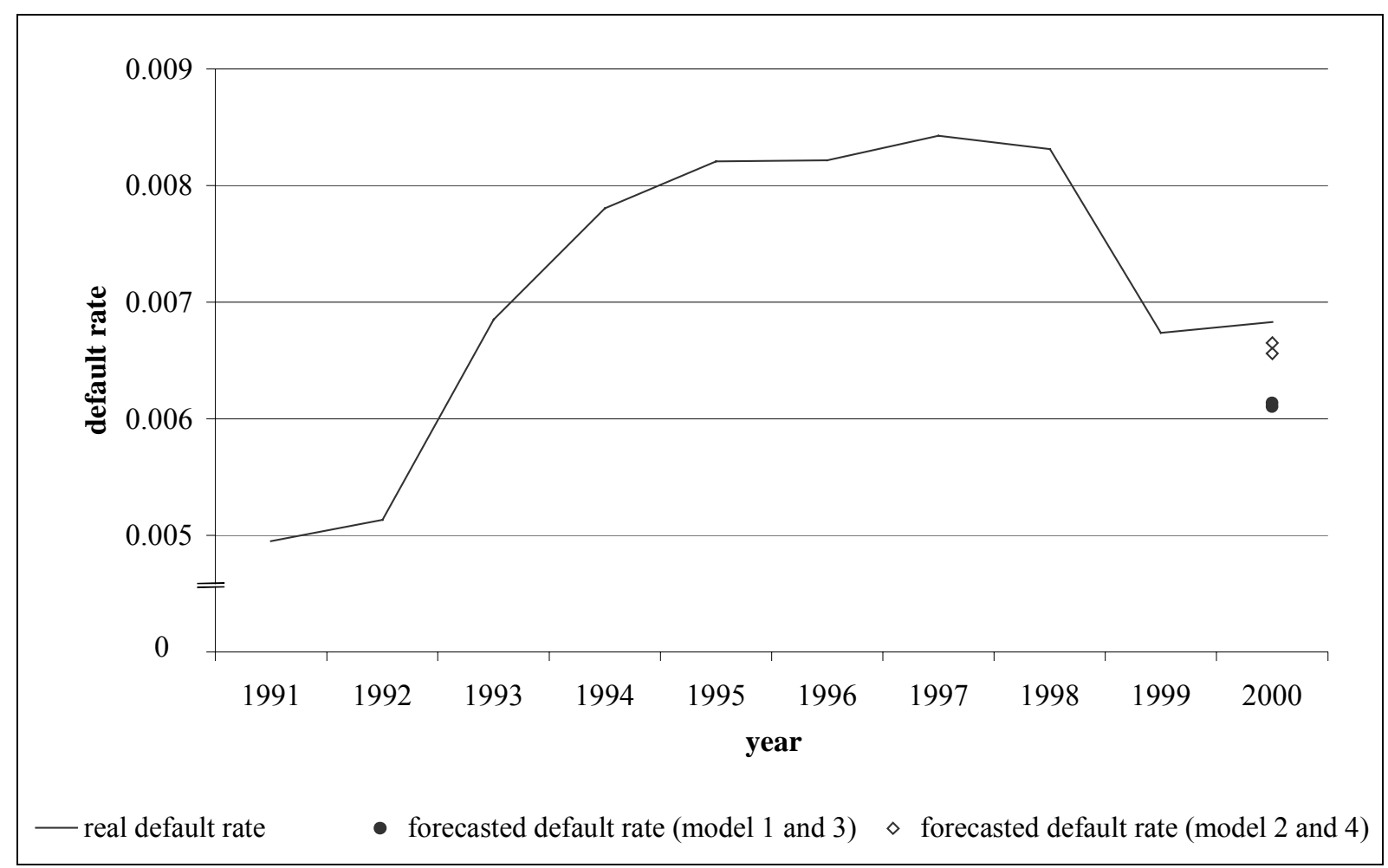

Chart 8: Real and forecasted default rates for year 2000, model 1 to model 4

Model 2 and model 4 which include macroeconomic variables, forecast the default rate more accurately than model 1 and model 3 which do not include macroeconomic variables. Note that the forecasted default rate for model 1 and 3 are very close to each other and therefore can not be differentiated in the chart. In other words, the calibration of the forecasted default probabilities would have been better if macroeconomic variables had been included in the respective model.

\subsection{Forecasting the default rate distribution}

The forecasted default probabilities and the estimated asset correlations can be aggregated to the forecasted default rate distribution. The forecasted default rate distribution can be interpreted as a loss distribution if the exposure at default and the loss given default equal one. 
Chart 9 compares the forecasted default rate distribution of model 1 without macroeconomic variables and model 2 with macroeconomic variables. Table 10 shows the respective mean forecasted default rate and the quantiles of the forecasted default rate distribution.

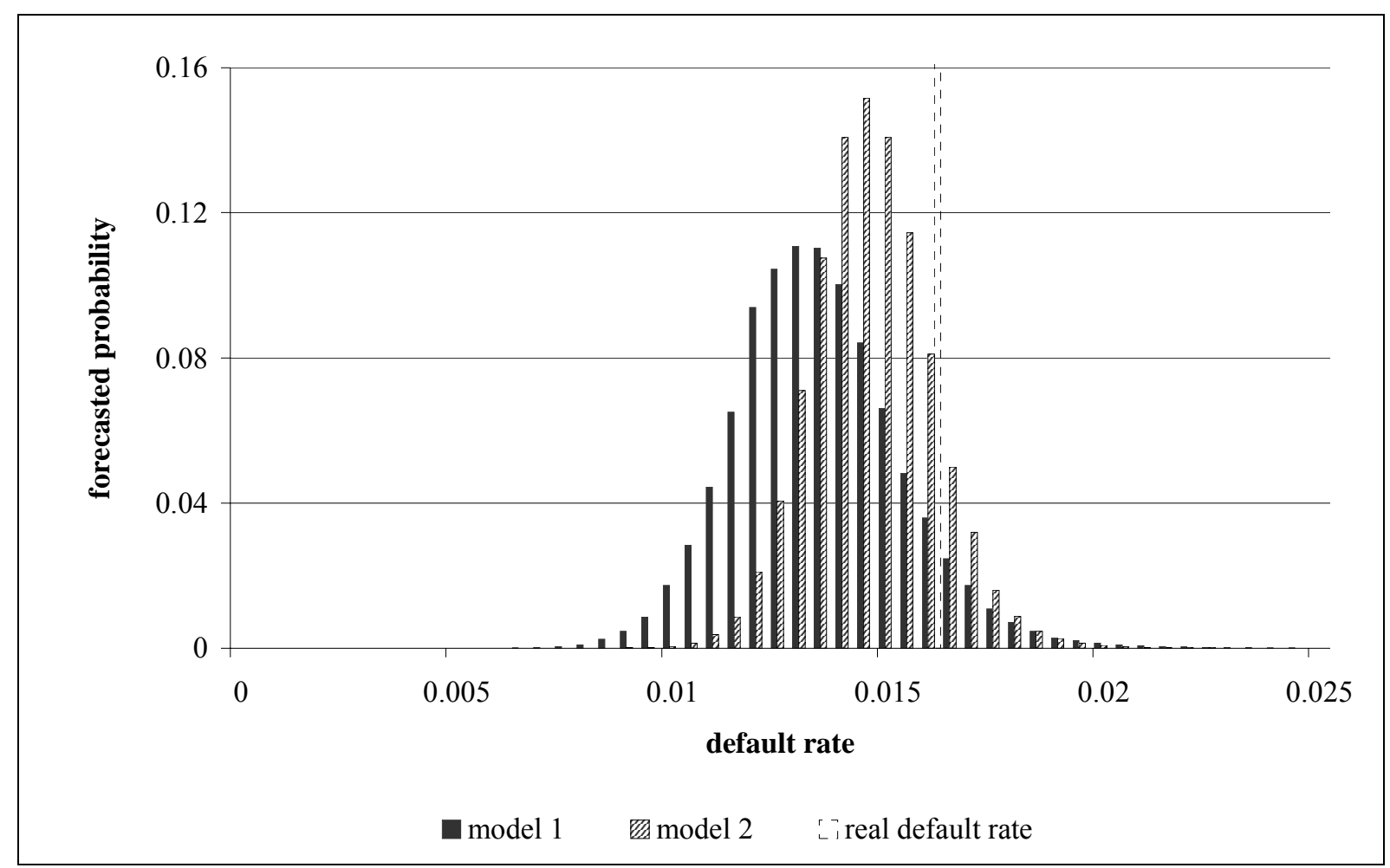

Chart 9: Forecasted default rate distribution, model 1 and model 2

\begin{tabular}{lcccc}
\hline & Mean forecasted default rate & $\mathbf{0 , 9 5 - Q .}$ & $\mathbf{0 , 9 9 - Q .}$ & $\mathbf{0 , 9 9 9 - Q . ~}$ \\
\hline Model 1 & 0.0134 & 0.0167 & 0.0187 & 0.0217 \\
Model 2 & 0.0146 & 0.0170 & 0.0183 & 0.0201 \\
\hline
\end{tabular}

Table 10: Mean forecasted default rate and quantiles of forecasted default rate distribution, model 1 and model 2

Again, it can be seen that the mean forecasted default rate for 2000 of model 2 is closer to the real default rate than that of model 1 . In addition, model 2 estimates a lower asset correlation 
which leads to a lower variance of the forecasted default rate. Hence, the portfolio credit risk is forecasted more accurately. Similar results are observed for model 3 and model 4 when multiple risk segments are assumed.

Chart 10 compares the forecasted default rate distribution of one risk segment model 1 and multiple risk segment model 3. Table 11 shows the respective mean forecasted default rate and the quantiles of the forecasted default rate distribution:

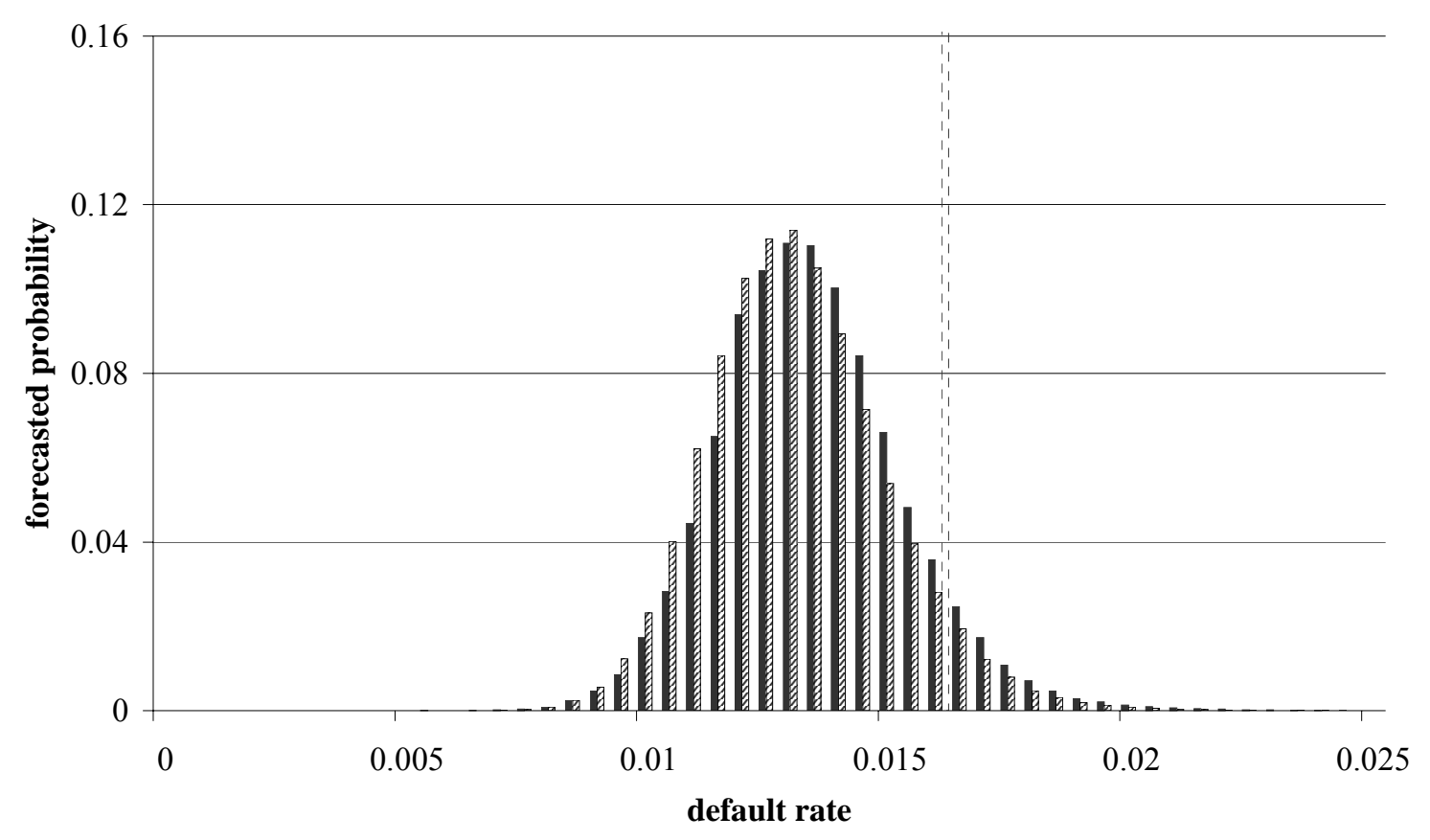

$\square$ model 1 model $3: 7$ real default rate

Chart 10: Forecasted default rate distribution, model 1 and model 3

\begin{tabular}{lcccc}
\hline & Mean forecasted default rate & $\mathbf{0 , 9 5 - Q .}$ & $\mathbf{0 , 9 9 - Q .}$ & $\mathbf{0 , 9 9 9 - Q .}$ \\
\hline Model 1 & 0.0134 & 0.0167 & 0.0187 & 0.0217 \\
Model 3 & 0.0131 & 0.0163 & 0.0181 & 0.0206 \\
\hline
\end{tabular}

Table 11: Mean forecasted default rate and quantiles of forecasted default rate distribution, model 1 and model 3 
The forecasted default rate distribution of model 1 is broader than that of model 3. Since default rate distributions generally broaden with a higher mean forecasted default rate, we cannot conclude that the assumption of multiple risk segments leads to more accurate credit portfolio risk forecasts. An examination of further periods is advisable.

\section{Summary}

The present paper describes an alternative methodology for forecasting credit portfolio risk.

We showed within this framework that

- individual default probabilities can be forecasted and asset (or default) correlations can be estimated, given the values of risk drivers that are observable in the point of time the forecasts are made.

- the inclusion of variables which are correlated with the business cycle improves the forecasts of default probabilities. The variance of the forecasted default rate decreases, i.e. the uncertainty of the forecasts is diminished.

- asset and default correlations depend on the factors used to model default probabilities. The better the point-in-time calibration of the estimated default probabilities, the smaller the estimated correlations. Thus, correlations and default probabilities should always be estimated simultaneously. 


\section{Appendix}

- Descriptive statistics firm-specific risk drivers

\begin{tabular}{cccccc}
\hline Ratio & Mean & Median & Standarddev. & Min & Max \\
\hline \hline ART & 34.5973 & 30.7526 & 25.8769 & 0 & 100 \\
APT & 34.8201 & 25.9981 & 30.1343 & 0 & 110 \\
CFT & 6.5248 & 4.7671 & 9.3863 & -15 & 25 \\
CRR & 12.2592 & 10.0036 & 16.2009 & -25 & 50 \\
ETA & 12.1587 & 9.7701 & 20.6234 & -35 & 60 \\
ITT & 48.1980 & 38.0972 & 44.0308 & 0 & 160 \\
RIE & 387.7100 & 218.4480 & 486.0730 & -650 & 1,400 \\
TTT & 0.0076 & 0.0074 & 0.0011 & 0.0062 & 0.0096 \\
\hline
\end{tabular}

Table 12: Data set Deutsche Bundesbank - summary statistics of firm-specific risk drivers

\begin{tabular}{l||cccccccc}
\hline & ART & APT & CFT & CRR & ETA & ITT & RIE & TTT \\
\hline \hline ART & 1.0000 & 0.2212 & -0.1255 & -0.0949 & -0.0400 & 0.0860 & -0.0333 & 0.0675 \\
APT & & 1.0000 & -0.0757 & -0.1780 & -0.2418 & 0.2460 & -0.2225 & -0.0584 \\
CFT & & & 1.0000 & 0.7423 & 0.1812 & -0.2627 & 0.3303 & -0.1666 \\
CRR & & & 1.0000 & 0.1476 & -0.2923 & 0.5290 & -0.0227 \\
ETA & & & & & 1.0000 & -0.0351 & 0.3423 & -0.0588 \\
ITT & & & & & & 1.0000 & -0.1924 & 0.0121 \\
RIE & & & & & & & 1.0000 & -0.0174 \\
TTT & & & & & & & & \\
\hline
\end{tabular}

Table 13: Data set Deutsche Bundesbank - Pearson correlations between firm-specific risk drivers 
- Descriptive statistics macroeconomic risk drivers

\begin{tabular}{lccccc}
\hline Variable & Mean & Median & Standarddev. & Min & Max \\
\hline \hline BCI & 88.311 & 85.028 & 7.483 & 82.29 & 103.36 \\
GOC & 0.0013 & 0.0054 & 0.0206 & -0.0270 & 0.0369 \\
Insolvency rate & 0.0072 & 0.0073 & 0.0013 & 0.0050 & 0.0084 \\
UER & 9.0537 & 9.3259 & 1.8706 & 6.3000 & 11.4830 \\
\hline
\end{tabular}

Table 14: Data set Deutsche Bundesbank - summary statistics of macroeconomic risk drivers

\begin{tabular}{l||cccc}
\hline & BCI & GOC & Insolvency Rate & UER \\
\hline \hline BCI & 1.0000 & 0.7734 & -0.8278 & -0.7685 \\
GOC & & 1.0000 & -0.7851 & -0.7662 \\
Insolvency Rate & & & 1.0000 & 0.6347 \\
UER & & & & 1.0000 \\
\hline
\end{tabular}

Table 15: Data set Deutsche Bundesbank - Pearson correlations between macroeconomic risk drivers 


\section{References}

Basel Committee on Banking Supervision, The New Basel Capital Accord, Consultative Document, April 2003, Bank for International Settlement, Basel.

Black, F./ Cox, J.C., Valuing Corporate Securities: Some Effects of Bond Indenture Provisions, 1976, Journal of Finance, 31, pp. 351- 367.

Black, F./ Scholes, M., The Pricing of Options and Corporate Liabilities, 1973, Journal of Political Economy, 81, pp. 637- 654.

Credit Suisse Financial Products, CreditRisk+ - A Credit Risk Management Framework, 1997, London.

Crosbie, P.J./ Bohn, J.R., Modeling Default Risk, 2002, KMV, San Francisco.

Davidson, R./ MacKinnon, J.G., Estimation and Inference in Econometrics, 1993, Oxford University Press, New York.

Dietsch, M./ Petey, J., The credit risk in SME loans portfolios: Modeling issues, pricing, and capital requirements, 2002, Journal of Banking and Finance, 26, pp. 303- 322 .

Engelmann, B./ Hayden, E./ Tasche, D., Testing for Rating Accuracy, 2003, Risk, 16, January, pp. 82-86.

Escott, P./ Glormann, F./ Kocagil, A.E., Moody's RiskCalc ${ }^{\top M}$ for Private Companies: the German Model, 2001, Moody’s Investors Service, New York.

Falkenstein, E., RiskCalc ${ }^{\mathrm{TM}}$ for Private Companies: Moody's Default Model, 2000, Moody's Investors Service, New York.

Finger, C.C., The One-Factor CreditMetrics Model in the New Basle Capital Accord, 2001, RiskMetrics Journal, pp. 9- 18.

Geske, R., The Valuation of Corporate Liabilities as Compound Options, 1977, Journal of Financial and Quantitative Analysis, 12, pp. 541- 552. 
Gupton, G.M./ Finger, C.C./ Bhatia, M., CreditMetrics Technical Document, 1997, J.P. Morgan \& Co., New York.

Longstaff, F.A./ Schwartz, E.S., A Simple Approach to Valuing Risky Fixed and Floating Rate Debt, 1995, Journal of Finance, 50, pp. 789- 819.

Lucas, D.J., Default Correlation and Credit Analysis, 1995, Journal of Fixed Income, pp. 76- 87.

Merton, R. C., On the Pricing of Corporate Debt: The Risk Structure of Interest Rates, 1974, Journal of Finance, 29, pp. 449- 470.

Merton, R. C., On the Pricing of Contingent Claims and the Modigliani-Miller Theorem, 1977 Journal of Financial Economics, 5, pp. 241- 249.

Pinheiro, J.C./ Bates, D.M., Approximations to the Log-Likelihood Function in the Nonlinear Mixed-Effects Model, 1995, Journal of Computational and Graphical Statistics, 4, pp. 12- 35.

Rabe-Hesketh, S./ Skrondal, A./ Pickles, A., Estimation of generalized linear mixed models, 2002, Stata Journal, 2, pp. 1- 21.

Scheule, H., Prognose von Kreditausfallrisiken, 2003, Dissertation, University of Regensburg, Uhlenbruch Verlag.

Shumway, T., Forecasting Bankruptcy More Accurately: A Simple Hazard Model, 2001, The Journal of Business, 74, pp. 101- 124.

Sobehart, J.R./ Keenan, S.C./ Stein, R.M., Benchmarking Quantitative Default Risk Models: A Validation Methodology, 2000, Moody's Investors Service, New York.

Wilson, T.C., Portfolio Credit Risk I, 1997a, Risk, 10, September, pp. 111- 117.

Wilson, T.C., Portfolio Credit Risk II, 1997b, Risk, 10, October, pp. 56- 61.

Zhou, C., An Analysis of Default Correlations and Multiple Defaults, 2001, Review of Financial Studies, 14, pp. 555- 576. 



\title{
The following Discussion Papers have been published since 2003:
}

\author{
Series 1: Studies of the Economic Research Centre
}

January 2003 Testing mean-variance efficiency in CAPM with possibly non-gaussian errors: an exact simulation-based approach

January 2003 Finite-sample distributions of self-normalized sums

January 2003 The stock return-inflation puzzle and the asymmetric causality in stock returns, inflation and real activity

February 2003 Multiple equilibrium overnight rates in a dynamic interbank market game

February 2003 A comparison of dynamic panel data estimators: Monte Carlo evidence and an application to the investment function

March 2003 A Vectorautoregressive Investment Model (VIM) And Monetary Policy Transmission: Panel Evidence From German Firms

2003 The international integration of money markets in the central and east European accession countries: deviations from covered interest parity, capital controls and inefficienCies in the financial sector

March 2003 The international integration of foreign exchange markets in the central and east European accession countries: speculative efficiency, transaction costs and exchange rate premiums

\author{
Marie-Claude Beaul \\ Jean-Marie Dufour \\ Lynda Khalaf
}

Jeong-Ryeol Kim

Jeong-Ryeol Kim

Jens Tapking

Andreas Behr

Joerg Breitung

Robert S. Chirinko

Ulf von Kalckreuth

Sabine Herrmann

Axel Jochem

Sabine Herrmann

Axel Jochem 
March 2003

Determinants of German FDI:

New Evidence from

Micro-Data

March 2003 On the Stability of

Different Financial Systems

April 2003 Determinants of German Foreign

Direct Investment in Latin American and

Asian Emerging Markets in the 1990s

June 2003 Active monetary policy, passive fiscal

policy and the value of public debt:

some further monetarist arithmetic

June 2003 Bidder Behavior in Repo Auctions

without Minimum Bid Rate:Dieter Nautz

Evidence from the Bundesbank

June 2003 Did the Bundesbank React to

Stock Price Movements?

$152003 \quad$ Money in a New-Keynesian model

estimated with German data

162003 Exact tests and confidence sets for the

tail coefficient of $\alpha$-stable distributions

172003 The Forecasting Performance of

German Stock Option Densities

182003 How wacky is the DAX? The changing

structure of German stock market volatility
Claudia Buch

Jörn Kleinert

Farid Toubal

Falko Fecht

Torsten Wezel

Leopold von Thadden

Tobias Linzert

Jörg Breitung

Martin T. Bohl

Pierre L. Siklos

Thomas Werner

Jana Kremer

Giovanni Lombardo

Thomas Werner

Jean-Marie Dufour

Jeong-Ryeol Kurz-Kim

B R Craig, E Glatzer,

J Keller, M Scheicher

Jelena Stapf

Thomas Werner 
12004 Foreign Bank Entry into Emerging Economies:

An Empirical Assessment of the Determinants

and Risks Predicated on German FDI Data Torsten Wezel

22004 Does Co-Financing by Multilateral Development

Banks Increase "Risky” Direct Investment in

Emerging Markets? -

Evidence for German Banking FDI Torsten Wezel

32004 Policy Instrument Choice and Non-Coordinated Giovanni Lombardo

Monetary Policy in Interdependent Economies Alan Sutherland

$42004 \quad$ Inflation Targeting Rules and Welfare

in an Asymmetric Currency Area Giovanni Lombardo

52004 FDI versus cross-border financial services: Claudia M. Buch

The globalisation of German banks Alexander Lipponer

$62004 \quad$ Clustering or competition? The foreign Claudia M. Buch

investment behaviour of German banks Alexander Lipponer

\section{Series 2: Banking and Financial Supervision}

$12003 \quad$ Measuring the Discriminative Power

B. Engelmann,

of Rating Systems

E. Hayden, D. Tasche

22003 Credit Risk Factor Modeling and

A. Hamerle,

the Basel II IRB Approach

T. Liebig, D. Rösch

$12004 \quad$ Forecasting Credit Portfolio Risk
A. Hamerle,
T. Liebig, H. Scheule 
